\title{
Evaluation of antidepressant-like activity of glycyrrhizin in mice
}

\author{
Dinesh Dhingra, Amandeep Sharma
}

Pharmacology Division,

Dept. Pharmaceutical Sciences,

Guru Jambheshwar University,

Hisar-125001 (Haryana), India.

Received: 6.5.2005

Revised: 29.7.2005

Accepted: 9.9.2005

Correspondence to: Dinesh Dhingra E-mail: din_dhingra@rediffmail.com

\begin{abstract}
Objective: To investigate the antidepressant-like effect of glycyrrhizin (glycyrrhizic acid ammonium) in mice.

Materials and Methods: Glycyrrhizin (1.5, 3.0 and $6.0 \mathrm{mg} / \mathrm{kg}$, i.p.) was administered once daily for seven successive days to separate groups of young male Swiss albino mice. The immobility periods of control and treated mice were recorded in forced swim test (FST) and tail suspension test (TST). Effect of sulpiride ( $50 \mathrm{mg} / \mathrm{kg}$, i.p.; a selective $\mathrm{D}_{2}$ receptor antagonist), prazosin $(62.5$ $\mu \mathrm{g} / \mathrm{kg}$, i.p.; an $\alpha_{1}$-adrenoceptor antagonist) and p-chlorophenylalanine $(100 \mathrm{mg} / \mathrm{kg}$, i.p.; an inhibitor of serotonin synthesis) on antidepressant-like effect of glycyrrhizin in TST was also studied. The antidepressant-like effect of glycyrrhizin was compared to that of imipramine $(15 \mathrm{mg} /$ $\mathrm{kg}$, i.p.) and fluoxetine (20 mg/kg, i.p.) administered for seven successive days.

Results: Glycyrrhizin produced significant antidepressant-like effect at a dose of $3.0 \mathrm{mg} / \mathrm{kg}$ administered for seven successive days, as indicated by reduction in the immobility times of mice in both FST and TST. Glycyrrhizin did not show significant effect on locomotor activity of mice. The efficacy of glycyrrhizin was found to be comparable to that of imipramine and fluoxetine. Sulpiride and prazosin significantly attenuated the glycyrrhizin-induced antidepressant-like effect in TST. On the other hand, p-chlorophenylalanine did not reverse antidepressant-like effect of glycyrrhizin. This suggests that the antidepressant-like effect of glycyrrhizin seems to be mediated by an increase in brain norepinephrine and dopamine, but not by an increase in serotonin. Conclusion: The results of the present study indicate the involvement of adrenergic and dopaminergic systems in the antidepressant-like effect of glycyrrhizin.
\end{abstract}

KEY WORDS: Depression, forced swim test, tail suspension test.

\section{Introduction}

Depression is a heterogeneous disorder that affects a person's mood, physical health and behavior. Patients with major depression have symptoms that reflect changes in brain monoamine neurotransmitters, specifically norepinephrine, serotonin and dopamine. ${ }^{[1]}$ Reserpine, an antihypertensive drug that depletes neuronal storage granules of norepinephrine, serotonin and dopamine, causes clinically significant depression in $15 \%$ or more of patients. ${ }^{[2]}$

Glycyrrhizin, a triterpene saponin, possess antiinflammatory ${ }^{[3]}$ antithrombotic, ${ }^{[4]}$ antiviral ${ }^{[5]}$ and antiulcer ${ }^{[6]}$ activities. Glycyrrhizic acid administered in drinking water at a concentration of $1 \mathrm{mg} / \mathrm{ml}$ for 10 days partially blocked the stress response and increased adaptation in rats. ${ }^{[7]}$ Glycyrrhizic acid competitively inhibits 11 beta-hydroxysteroid dehydrogenase type-2 (11 beta-HSD2) enzymatic activity. ${ }^{[8]}$ Glycyrrhizic acid is hydrolysed in the intestine to the pharmacologically active compound glycyrrhetic acid, which inhibits the enzyme 11 beta-hydroxysteroid dehydrogenase (in the direction of cortisol to cortisone) as well as some other enzymes involved in the metabolism of corticosteroids.
Inhibition of 11 beta-hydroxysteroid dehydrogenase leads to increased cortisol levels in the kidneys and in other mineralocorticoid-selective tissues. Since cortisol, which occurs in much larger amounts than aldosterone, binds with the same affinity as aldosterone to the mineralocorticoid receptor, the result is a hypermineralocorticoid effect of cortisol leading to sodium retention, potassium loss and suppression of the rennin-angiotensin-aldosterone system, thus leading to adverse effects such as hypertension and oedema. There is apparently a great individual variation in the susceptibility to glycyrrhizic acid. A daily intake of $10 \mathrm{mg}$ glycyrrhizic acid would represent a safe dose for most healthy adult human beings. However, considerable number of individuals, who consume large amounts of glycyrrhizic acid, is exposed to the risk of developing adverse effects. ${ }^{|9|}$ The 11 beta-HSD2 rapidly inactivates glucocorticoids in placenta and many foetal tissues, thus acting as a 'barrier' to maternal steroids. Inhibition of 11 beta-HSD2 by carbenoxolone (the succinyl ester of glycyrrhetinic acid), permanently programs amygdala glucocorticoid receptor mRNA expression and produces anxiety-like behaviour in the offspring ${ }^{10}$. 
Glycyrrhizin inhibits monoamine oxidase (MAO), ${ }^{[11]}$ thereby increasing the levels of monoamines like epinephrine and dopamine in brains of mice. Abundant evidence indicates that MAO inhibitors increase the concentrations of norepinephrine, 5-hydroxytryptamine (serotonin) and dopamine within the neuronal synapse through the inhibition of MAO enzyme and have antidepressant effects. ${ }^{[12], ~}{ }^{13]}$ Therfore, the present study was undertaken (i) to investigate the effect of glycyrrhizin on depression in mice employing forced swim test (FST) and tail suspension test (TST) and (ii) to explore the possible underlying mechanisms of antidepressant-like activity of the glycyrrhizin. Standard antidepressant drugs such as fluoxetine, a selective serotonin reuptake inhibitor, and imipramine, a tricyclic antidepressant were employed to standardize the animal models of depression and to compare the antidepressant efficacy of glycyrrhizin. $( \pm)$ sulpiride $\left(\mathrm{D}_{2}\right.$-receptor antagonist), prazosin $\left(\alpha_{1}\right.$-adrenoceptor antagonist), and p-chlorophenylalanine (serotonin synthesis inhibitor) were used to evaluate the probable mechanisms of antidepressant-like effect of glycyrrhizin.

\section{Materials and Methods}

\section{Study design}

The design of this experimental study was comparative and parallel group. Animals were divided into 24 groups and each group comprised of a minimum of five mice. Glycyrrhizin was administered in three different doses $(1.5,3.0$ and $6.0 \mathrm{~m} / \mathrm{kg}$, i.p.) to different groups of mice. The dose selection of glycyrrhizin (glycyrrhizic acid ammonium) was based on the earlier study, which stated that repeated oral administration (30 times) of maximum daily therapeutic dose $(7 \mathrm{mg} / \mathrm{kg}$ ) and in a fourfold dose $(28 \mathrm{mg} / \mathrm{kg})$ did not cause signs of intoxication, essential changes in the hematological and integral parameters, shifts in the activity of serum enzymes, morphological changes in the cell structures of the internal organs. ${ }^{[14]}$ The experimental protocol was approved by the Institutional Animals Ethics Committee before the start of the study.

\section{Animals}

Swiss male albino mice (3 months old), weighing around $25 \mathrm{~g}$ and procured from disease free small animal house, CCS Haryana Agriculture University, Hisar (Haryana, India), were used in the present study. Animals had free access to food and water, and were maintained under standard laboratory conditions with a natural light and dark cycle. Food given to mice consisted of wheat flour kneaded with water and mixed with small amount of refined vegetable oil. The animals were acclimatized for at least 5 days before behavioural experiments. Experiments were carried out between 09:00 and 15:00 h.

\section{Drugs and chemicals}

Glycyrrhizin (glycyrrhizic acid ammonium), ( \pm ) sulpiride, prazosin hydrochloride, DL-p-chlorophenylalanine, imipramine hydrochloride (Sigma-Aldrich, St. Louis, USA) fluoxetine hydrochloride (Ranbaxy Laboratories, Gurgaon, India), acetic acid glacial (Central Drug House PVt. Ltd., New Delhi, India), sodium hydroxide pellets (Hi-Media, Mumbai, India) were used in the present study.

\section{Vehicle}

Glycyrrhizic acid ammonium was dissolved in hot normal saline $\left(60-62^{\circ} \mathrm{C}\right)$. Fluoxetine hydrochloride, imipramine hydrochloride and prazosin hydrochloride were dissolved separately in normal saline $(0.9 \%$ sodium chloride). Sulpiride was dissolved in normal saline followed by addition of one drop of glacial acetic acid. p-chlorophenylalanine (p-CPA) was dissolved in minimum quantity of $0.1 \mathrm{~N}$ sodium hydroxide and $\mathrm{pH}$ was adjusted to 7 with $0.1 \mathrm{~N}$ hydrochloric acid. Volume of i.p. injection was $1 \mathrm{ml} / 100 \mathrm{~g}$ of mouse.

\section{Laboratory models for testing antidepressant activity}

Forced swim test (FST): Behaviour despair was proposed as a model to test for antidepressant activity by Porsolt $e t$ $a l^{[15], ~[16]}$ Mice were forced to swim individually in a glass jar $\left(25 \times 12 \times 25 \mathrm{~cm}^{3}\right)$ containing fresh water of $15 \mathrm{~cm}$ height and maintained at $25^{\circ} \mathrm{C}\left( \pm 3^{\circ} \mathrm{C}\right)$. After an initial $2 \mathrm{~min}$ period of vigorous activity, each animal assumed a typical immobile posture. A mouse was considered to be immobile when it remained floating in the water without struggling, making only minimum movements of its limbs necessary to keep its head above water. The total duration of immobility was recorded during the next 4 min of a total 6 min test. The changes in immobility duration were studied after administering drugs in separate groups of animals. Each animal was used only once.

Tail suspension test (TST): The total duration of immobility induced by tail suspension was measured according to the method described by Steru et al ${ }^{[17]}$ as a facile means of evaluating potential antidepressants. Mice were suspended on the edge of a table $50 \mathrm{~cm}$ above the floor by the adhesive tape placed approximately $1 \mathrm{~cm}$ from the tip of the tail. Immobility time was recorded during a 6 min period. ${ }^{[18]}$ Animal was considered to be immobile when it did not show any movement of body and hanged passively.

\section{Study groups}

Using FST: Group I (control group): normal saline (1 ml/ 100 g). Group II: Fluoxetine $(20 \mathrm{mg} / \mathrm{kg}$, i.p.). Group III: Imipramine (15 mg/kg, i.p.). Groups IV-VI: Glycyrrhizin (1.5, 3.0 and $6.0 \mathrm{mg} / \mathrm{kg}$, respectively). In all these groups, respective drug treatment (i.p.) was given for seven successive days. After $60 \mathrm{~min}$ of the last dose, the immobility period was recorded.

Using TST: Group VII (control group for one day treatment): normal saline $(1 \mathrm{ml} / 100 \mathrm{~g})$. Groups VIII-X: Glycyrrhizin (1.5, 3.0 and $6.0 \mathrm{mg} / \mathrm{kg}$, respectively). In all these groups, respective drug treatment (i.p.) was given only once. After $60 \mathrm{~min}$ of administration, the immobility period was recorded.

Group XI (control group for 7 days treatment): normal saline $(1 \mathrm{ml} / 100 \mathrm{~g})$. Group XII: Fluoxetine $(20 \mathrm{mg} / \mathrm{kg}$, i.p.). Group XIII: Imipramine (15 mg/kg, i.p.). Groups XIV-XVI: Glycyrrhizin $(1.5,3.0$ and $6.0 \mathrm{mg} / \mathrm{kg}$, respectively). In all these groups, respective drug treatment (i.p.) was given for seven successive days. After 60 min of the last dose, the immobility period was recorded.

Group XVII: Normal saline was injected i.p. for seven successive days and then sulpiride $(50 \mathrm{mg} / \mathrm{kg}$, i.p.) was administered on the seventh day after $30 \mathrm{~min}$ of last injection of normal saline. The animals were subjected to TST after 30 min of sulpiride injection.

Group XVIII: Glycyrrhizin $(3.0 \mathrm{mg} / \mathrm{kg})$ was administered i.p. for seven successive days and then sulpiride $(50 \mathrm{mg} / \mathrm{kg}$, i.p.) was administered on the seventh day after 30 min of last 
injection of glycyrrhizin. The animals were subjected to TST after $30 \mathrm{~min}$ of sulpiride injection.

Group XIX: Normal saline was injected i.p. for seven successive days and then prazosin $(62.5 \mu \mathrm{g} / \mathrm{kg}$, i.p.) was administered on the seventh day after 30 min of last injection of normal saline. The animals were subjected to TST after 30 min of prazosin injection.

Group XX: Glycyrrhizin $(3.0 \mathrm{mg} / \mathrm{kg})$ was administered i.p. for seven successive days and then prazosin $(62.5 \mu \mathrm{g} / \mathrm{kg}$, i.p.) was administered on the seventh day after 30 min of last injection of glycyrrhizin. The animals were subjected to TST after 30 min of prazosin injection.

Group XXI: Normal saline was injected i.p. for three successive days to mice. From the fourth day to seventh day, p-CPA $(100 \mathrm{mg} / \mathrm{kg}$, i.p.) was administered after $30 \mathrm{~min}$ of injection of normal saline. The animals were subjected to TST after 30 min of p-CPA injection on the seventh day.

Group XXII: Glycyrrhizin $(3.0 \mathrm{mg} / \mathrm{kg}$ ) was administered i.p. for three successive days to mice. From the fourth day to seventh day, p-CPA (100 mg/kg, i.p.) was administered after 30 min of i.p. injection of glycyrrhizin. The animals were subjected to TST after 30 min of p-CPA injection on the seventh day.

Group XXIII: Fluoxetine $(20 \mathrm{mg} / \mathrm{kg})$ was injected i.p. for three successive days to mice. From the fourth day to seventh day, $p$-CPA (100 mg/kg, i.p.) was administered after $30 \mathrm{~min}$ of injection of fluoxetine. The animals were subjected to TST after 30 min of p-CPA injection on the seventh day.

Group XXIV: Effect of glycyrrhizin $(3.0 \mathrm{mg} / \mathrm{kg}$, i.p.) on locomotor function of mice was studied using a photoactometer (INCO, Ambala, India) to rule out the increase in locomotor performance of mice. The difference in the locomotor activity scores was noted before and after the administration of glycyrrhizin.

\section{Statistical analysis}

All results are expressed as mean \pm SEM. All the groups were analysed using one-way ANOVA followed by Dunnett's test. The locomotor activity scores were subjected to Student's paired $t$-test. $\mathrm{P}<0.05$ was considered significant.

\section{Results}

\section{Effect on immobility periods in FST and TST}

Single dose $(1.5,3.0$ and $6.0 \mathrm{mg} / \mathrm{kg}$ ) of glycyrrhizin did not have significant effect on immobility periods of mice as compared to control in TST [Figure 2]. Glycyrrhizin (1.5 and $6.0 \mathrm{mg} / \mathrm{kg}$ ) administered i.p. for seven successive days also did not have significant effect on immobility periods as compared to control in both FST and TST. On the other hand, glycyrrhizin in a dose of $3.0 \mathrm{mg} / \mathrm{kg}$ administered i.p. for seven successive days significantly decreased immobility period as compared to control in both FST and TST, indicating significant antidepressant-like effect. Imipramine $(15 \mathrm{mg} / \mathrm{kg}$, i.p.) and fluoxetine $(20 \mathrm{mg} / \mathrm{kg}$, i.p.) for seven successive days significantly reduced the immobility periods as compared to respective controls in both FST and TST [Figures 1 and 2].

Effect of combination of glycyrrhizin with sulpiride, prazosin and p-CPA on immobility periods in TST

Sulpiride $(50 \mathrm{mg} / \mathrm{kg}$, i.p.) and prazosin $(62.5 \mu \mathrm{g} / \mathrm{kg}$, i.p.) alone significantly increased the immobility period while p-
Figure 1. Effect of glycyrrhizin on immobility period of mice using forced swim test (FST)

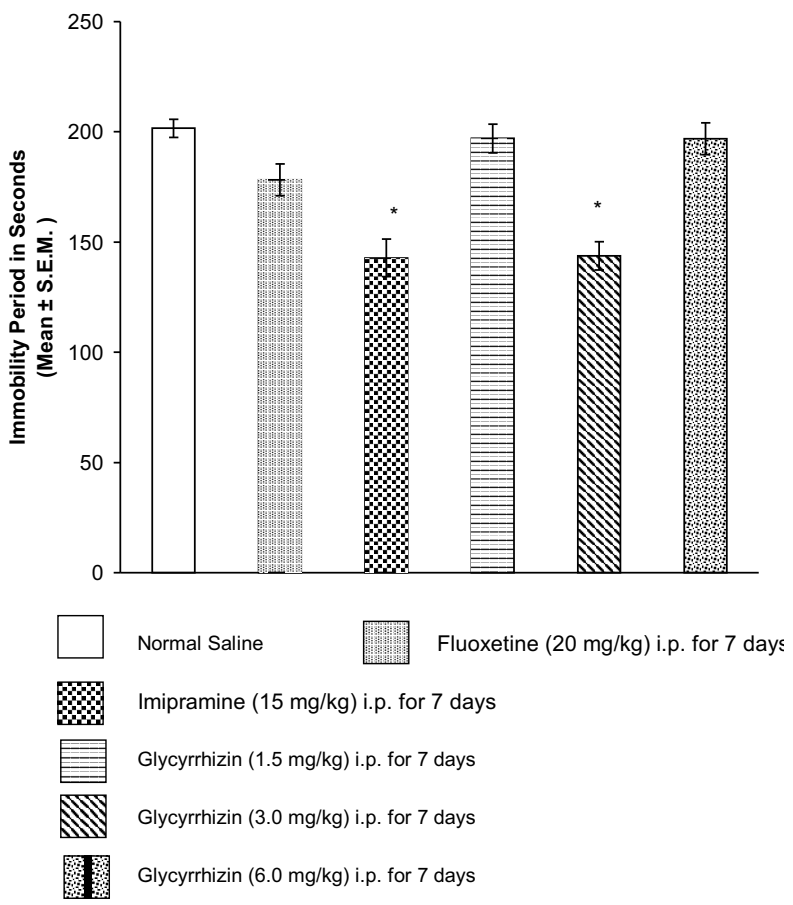

$\mathrm{n}=5$ in each group; One-way ANOVA $(\mathrm{F}=15.89 ; \mathrm{df}=5,24 ; \mathrm{p}<0.001)$ *indicates $p<0.05$ as compared to normal saline treated control group (Dunnett's test).

Figure 2. Effect of Glycyrrhizin on immobility period of mice using tail suspension test (TST)

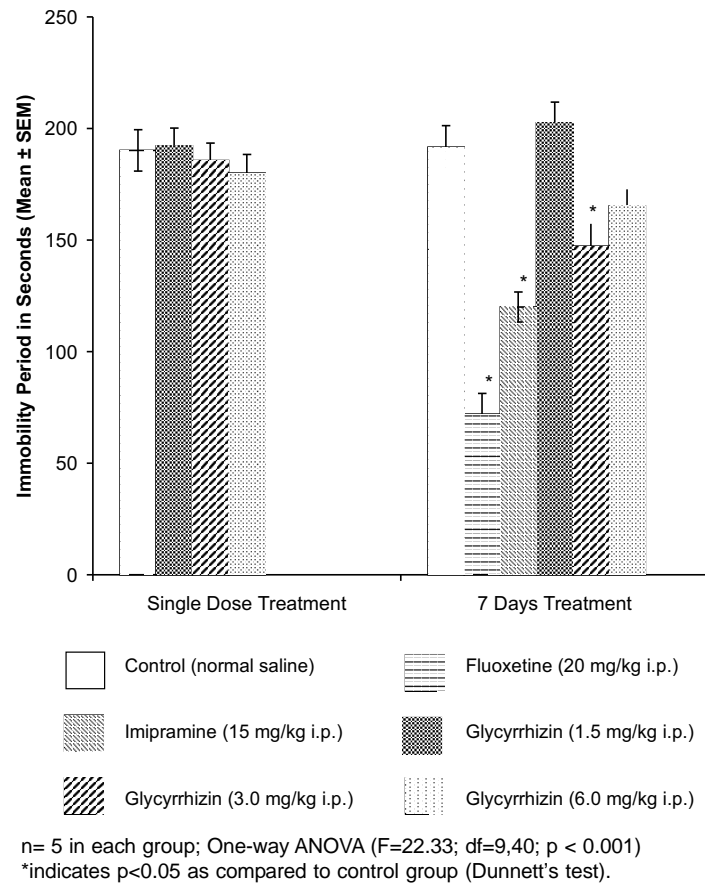

CPA alone did not have significant effect as compared to control. Pretreatment of animals with sulpiride or prazosin significantly blocked the decrease of immobility time produced by glycyrrhizin. On the other hand, pretreatment of mice with 


\section{Table 1} Effect of combination of glycyrrhizin with sulpiride, prazosin and
p-CPA on immobility period in TST

\begin{tabular}{|c|c|c|c|}
\hline Group & Treatment & Dose $\left(\mathrm{kg}^{-1}\right)^{*}$ & $\begin{array}{l}\text { Immobility period } \\
\text { mean }(\text { sec }) \pm S E M\end{array}$ \\
\hline XI & Control (Normal saline) & 10 & $191.6 \pm 9.7$ \\
\hline$X V$ & Glycyrrhizin for 7 days & 3.0 & $147.2 \pm 10.1^{\mathrm{a}}$ \\
\hline \multirow[t]{2}{*}{ XVII } & Normal saline + & 10 & \\
\hline & Sulpiride & 50 & $240 \pm 6.9^{a}$ \\
\hline \multirow[t]{2}{*}{ XVIII } & Glycyrrhizin for 7 days + & 3.0 & \\
\hline & Sulpiride & 50 & $208.2 \pm 8.5^{b}$ \\
\hline \multirow[t]{2}{*}{ XIX } & Normal saline + & 10 & \\
\hline & Prazosin & 0.0625 & $223.6 \pm 4.4^{\mathrm{a}}$ \\
\hline \multirow[t]{2}{*}{$X X$} & Glycyrrhizin for 7 days + & 3.0 & \\
\hline & Prazosin & 0.0625 & $209.4 \pm 8.0^{b}$ \\
\hline \multirow[t]{2}{*}{$X X I$} & Normal saline + & 10 & \\
\hline & $\mathrm{p}-\mathrm{CPA}$ & 100 & $207.2 \pm 4.9$ \\
\hline \multirow[t]{2}{*}{ XXII } & Glycyrrhizin for 7 days + & 3.0 & \\
\hline & $\mathrm{p}-\mathrm{CPA}$ & 100 & $150.6 \pm 5.6$ \\
\hline XII & Fluoxetine for 7 days & 20 & $72.0 \pm 9.3^{a}$ \\
\hline \multirow[t]{2}{*}{ XXIII } & Fluoxetine + & 20 & \\
\hline & $\mathrm{p}-\mathrm{CPA}$ & 100 & $163.4 \pm 4.8^{c}$ \\
\hline One-way & $\mathrm{F}$ & & 42.98 \\
\hline \multirow[t]{2}{*}{ ANOVA } & df & & 9,40 \\
\hline & $P$ & & $<0.0001$ \\
\hline
\end{tabular}

$\mathrm{n}=5$ in each group * the dose of normal saline is expressed in $\mathrm{mL}$, for other drugs it is in mg. ${ }^{\text {a }}<0.05$ as compared to normal saline (Dunnett's test). ${ }^{\text {b }} \mathrm{P}<0.05$ as compared to glycyrrhizin alone (Dunnett's test). ${ }^{c} \mathrm{P}<0.05$ as compared to fluoxetine alone (Dunnett's test).

p-CPA (100 mg/kg, i.p.) did not significantly reverse the decrease in immobility period produced by glycyrrhizin. However, pretreatment of mice with p-CPA (100 mg/kg, i.p.) significantly reversed decrease of immobility period produced by fluoxetine [Table 1].

\section{Effect on locomotor activity}

There was no significant effect on locomotor activity of mice $(426 \pm 14.7)$ when treated with glycyrrhizin $(3.0 \mathrm{mg} / \mathrm{kg}$, i.p.) for seven successive days as compared to control (before treatment) $(434.2 \pm 9.7)$.

\section{Discussion}

In the present study, glycyrrhizin $(3.0 \mathrm{mg} / \mathrm{kg})$ produced significant antidepressant-like effect in mice in both FST and TST. Both these models of depression are widely used to screen new antidepressant drugs. ${ }^{[15]-[17], ~[19]}$ These tests are quite sensitive and relatively specific to all major classes of antidepressant drugs including tricyclics, serotonin-specific reuptake inhibitors, monoamine oxidase (MAO) inhibitors and atypicals. ${ }^{[15],[17],[20]}$ In FST, mice are forced to swim in a restricted space from which they cannot escape, and are induced to a characteristic behaviour of immobility. This behaviour reflects a state of despair that can be reduced by several agents, which are therapeutically effective in human depression. The TST also induces a state of immobility in animals like that in FST. This immobility, referred as behavioural despair in animals, which is claimed to reproduce a condition similar to human

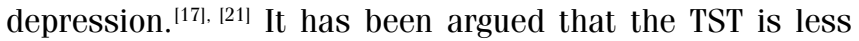
stressful than FST and has greater pharmacological sensitivity. ${ }^{\mid 22]}$

The antidepressant-like effect of glycyrrhizin seems not to be associated with any motor effects, since it did not show significant change in locomotor function of mice as compared to control. This indicates that increased motor activity was not involved in the action seen in both FST and TST, and confirms the assumption that the antidepressant-like effect of glycyrrhizin is specific. The precise mechanisms by which glycyrrhizin produced antidepressant-like effect are not completely understood. However, according to our results, the antidepressant-like effect of glycyrrhizin was significantly reversed by the treatment of animals with prazosin (an $\alpha_{1}-$ adrenoceptor antagonist) and sulpiride (a selective dopamine $\mathrm{D}_{2}$-receptor antagonist) when tested in TST. This suggests that glycyrrhizin might produce antidepressant-like effect by interaction with $\alpha_{1}$-adrenoceptors and dopamine $\mathrm{D}_{2}$-receptors, thereby increasing the levels of norepinephrine and dopamine in brains of mice. However, p-CPA (a serotonin synthesis inhibitor) did not significantly attenuate the antidepressantlike effect of glycyrrhizin in TST, suggesting that antidepressant effect of glycyrrhizin is not mediated through serotonergic system. On the other hand, p-CPA significantly reversed the antidepressant effect of fluoxetine (a specific serotonin reuptake inhibitor) in TST, suggesting that fluoxetine has antidepressant effect through the serotonergic system.

Since glycyrrhizin has MAO inhibiting activity, ${ }^{[1]}$ therefore, antidepressant-like effect of glycyrrhizin in mice might be through increase in the brain levels of monoamines like epinephrine and dopamine by inhibiting monoamine oxidase. Thus, it may be concluded that glycyrrhizin produced antidepressant-like effect in mice in both FST and TST, and this effect seems most likely to be mediated through an interaction with adrenergic and dopaminergic systems. The efficacy of the glycyrrhizin was comparable to that of imipramine and fluoxetine.

\section{Acknowledgments}

Authors are thankful to Dr. R.P. Bajpai, Honorable Vice Chancellor, Guru Jambheshwar University, Hisar, for his encouragement. We are also grateful to Mr. Rajinder Kumar Harna, Dist. Drugs Inspector, Fatehabad (Haryana, India) for his valuable suggestions. Gift sample of fluoxetine hydrochloride by Ranbaxy Labs., Gurgaon, is gratefully acknowledged.

\section{References}

1. Gold PW, Goodwin FK, Chrousus GP. Clinical and biochemical manifestations of depression in relation to the neurobiology of stress: Part 1. N Engl J Med 1988;319:348-53.

2. Goodwin FK, Bunney WE. Depressions following reserpine: A re-evaluation. Sem Psychiatry 1971;3:435-48.

3. Akamatsu H, Komura J, Asada Y, Niwa Y. Mechanism of anti-inflammatory action of glycyrrhizin: effect on neutrophil functions including reactive oxygen species generation. Planta Med 1991;57:119-21.

4. Mendes-Silva W, Assafim M, Ruta B, Monteiro RQ, Guimaraes JA, Zingali RB. Antithrombotic effect of glycyrrhizin, a plant-derived thrombin inhibitor. Thromb Res 2003;112:93-8.

5. Hirabayashi K, Iwata S, Matsumoto H, Mori T, Shibata S, Baba M, et al. Antiviral activity of glycyrrhizin and its modified compounds against human immunodeficiency virus type1 and herpes simplex type 1 in vitro. Chem Pharm Bull 1991;39:112-15

6. Krausse R, Bielenberg J, Blaschek W, Ullmann U. In vitro anti-Helicobacter 
pylori activity of Extractum liquiritiae, glycyrrhizin and its metabolites. $\mathrm{J}$ Antimicrob Chemother 2004;54:243-6.

7. Ainsah $\mathrm{O}$, Nabishah BM, Osman $\mathrm{CB}$, Khalid BA. Short- and long-term effects of glycyrrhizic acid in repetitive stress. Clin Exp Pharmacol Physiol 1999;26: 444-8.

8. Tanahashi T, Mune T, Morita H, Tanahashi H, Isomura Y, Suwa T, et al. Glycyrrhizic acid suppresses type 211 beta-hydroxysteroid dehydrogenase expression in vivo. J Steroid Biochem Mol Biol 2002;80:441-7.

9. Stormer FC, Reistad R, Alexander J. Glycyrrhizic acid in liquorice-evaluation of health hazard. Food Chem Toxicol 1993;31:303-12.

10. Welberg LA, Seckl JR, Holmes MC. Inhibition of 11beta-hydroxysteroid dehydrogenase, the foeto-placental barrier to maternal glucocorticoids, permanently programs amygdala GR mRNA expression and anxiety-like behaviour in the offspring. Eur J Neurosci 2000;12:1047-54.

11. Hatano T, Fukuda T, Miyase T, Noro T, Okuda T. Phenolic constituents of liquorice. III. Structures of glicoricone and licofuranone, and inhibitory effects of licorice constituents on monoamine oxidase. Chem Pharm Bull (Tokyo) 1991;39:1238-43.

12. Bryant SG, Brown CS. Current concepts in clinical therapeutics: major affective disorders, part-2. Clin Pharm 1986;5:385-95.

13. Kanazawa I. Short review on monoamine oxidase and its inhibitors. Eur Neurol 1994;34:36-9.

14. Antov G, Khalkova Zh, Mikhailova A, Zaikov Kh, Burkova T. The toxicological characteristics of ammonium glycyrrhizinate (glycyram): A study of its acute and subacute toxicity. Eksp Klin Farmakol 1997;60:65-7.

15. Porsolt RD, Bertin A, Jalfre M. Behavioral despair in mice: A primary screening test for antidepressants. Archives Internationales de Pharmacodynamie et de Therapie 1977;229:327-36.

16. Porsolt RD, Anton G, Deniel M, Jalfre M. Behavioral despair in rats: a new animal model sensitive to antidepressant treatments. Eur J Pharmacol 1978;47: 379-91.

17. Steru L, Chermat R, Thierry B, Simon P. The tail suspension test: A new method for screening antidepressants in mice. Psychopharmacol 1985;85:367-70.

18. Rodrigues AS, da Silva GL, Mateussi AS, Fernandes ES, Miguel OG, Yunes $\mathrm{RA}$, et al. Involvement of monoaminergic system in the antidepressant-like effect of the hydroalcoholic extract of Siphocampylus verticillatus. Life Sci 2002;70:1347-58.

19. Porsolt RD, Bertin A, Blavet N, Deniel M, Jalfre M. Immobility induced by forced swimming in rats: Effects of agents, which modify central catecholamine and serotonin activity. Eur J Pharmacol 1979;57:201-10.

20. Detke MJ, Rickels M, Lucki I. Active behavior in the rat forced swimming test differentially produced by serotonergic and noradrenergic antidepressants. Psychopharmacol 1995;121:66-72.

21. Willner P. The validity of animal models of depression. Psychopharmacol 1984;83:1-16

22. Thierry B, Steru L, Simon P, Porsolt RD. The tail suspension test: ethical considerations. Psychopharmacol 1986;90:284-5.

\title{
IPS WEBSITE \\ IPS has launched a website \\ www.gsips.org
}

Features: Online registration, Constitution and Member list at one click.

\section{Contact point:}

\author{
Dr. Prakash V. Diwan \\ General Secretary, IPS \\ Head, Pharmacology Division \\ Indian Institute of Chemical Technology \\ Hyderabad -500 007 \\ E.mail: diwan@iict.res.in, diwan_prakash@rediffmail.com
}

